\title{
Differentiation for Equity
}

\author{
Andrea Smith \\ University of West Georgia \\ Cliff Chestnutt \\ University of West Georgia
}

\begin{abstract}
Dosch and Zidon (2014) highlight the negative impact of traditional pedagogical approaches on student learning by examining the power of practices and rhetoric that blame students for academic failure and ultimately reproduce traditional power structures in higher education. As diversity in higher education increases, the use of traditional teaching approaches that encompass one-size-fits-all, teacher-centered approaches must be reconsidered to ensure equity-based practices to support differentiation in the classroom. When considering differentiation as a means to disrupt traditional forms of pedagogy in higher education, however, research is often limited in its ability to provide practical strategies that are relative to the college setting (Weingarten \& Deller, 2011). As such, this article provides a review of differentiation in education and outlines applied examples of differentiation that can be used in college classrooms to promote equity.
\end{abstract}

Keywords: differentiation, equity, higher education, diversity, culturally responsive pedagogy

\section{DIFFERENTIATED INSTRUCTION FOR EQUITY}

Diversity among the student population in higher education has increased due to the varied life and educational experiences of students. However, little change has occurred in the diversity of instructional planning and presentation strategies to support diverse student populations. Pliner and Johnson (2004) state, "Higher education in the United States has been primarily available to a professional class that was white, able-bodied, heterosexual, Christian, and male" (p. 106). Given this, it is essential for college instructors to examine their teaching practices to implement equitable ones that support learning and are relevant to the diverse demographics present in their classrooms. Although research highlights the shift to establish more equitable classrooms in recent years, little has changed to address the curriculum and instructional methods that impact student engagement and achievement (Dosch and Zidon, 2014).

A solution to creating equitable classrooms involves the use of differentiation. The use of differentiation in the classroom is a pathway to equity because it calls on teachers to understand the needs of their students and provide diverse practices to support student needs. While differentiation has been researched by numerous scholars (Ernst \& Ernst, 2005; Livingston, 2006; Sparks, 2015; Tukbure, 2011), it often fails to illuminate practices that translate to classrooms in higher education. Additionally, traditional ideas about differentiation neglect to account for the impact teacher beliefs and the culture of students play in the learning process (Santamaria, 2009). Essentially, differentiation for equity must entail teaching all the 
students in the classroom, striving to structure the classroom environment that maximizes access to meaningful content, allowing for personal connections that produce critical thinking and engagement.

\section{DIFFERENTIATION AS A MEANS FOR EQUITY}

Equity entails ensuring that every student has access to the curriculum, assessment, pedagogy, and challenges he or she needs based on the recognition and response to individual differences and the sociopolitical context of teaching and learning (McGee Banks \& Banks, 1995). While many educators refer to equity as a right that all students should garner, the reality of this ideal right for all students is often overlooked and undervalued in our education system. As previously noted, a one-size-fits-all approach to teaching and learning reinforces normative pedagogies and marginalizes diverse groups of students and perspectives. In particular, such ideal rights are often infringed on among students and groups who do not fit white, middle class, heterosexual, and English speaking models. Such encroachments create a need for equitable approaches to education that benefit all students by implementing strategies to support each learner with specific resources and access to opportunities that will enable success. As such, differentiation as an equitable pedagogical tool becomes integral for achieving an inclusive classroom environment.

As diversity in higher education increases, teachers must find ways to adapt the curriculum and instructional methods to support student learning and access to content. While there are various methods for addressing adaptation and access to support student learning, Beamish \& Saggers (2013) posits differentiation as a useful tool for ensuring equity in the classroom. From this perspective, differentiation would seem to be a moral obligation. Tomlinson (2016) notes:

Differentiation is effective attention to the learning needs of each student. The purpose of developing a differentiated classroom is to make sure there are opportunities and support for each student to learn essential knowledge and skills as effectively and efficiently as possible. The key is getting to know each student and orchestrating the learning environment, curriculum, assessments, and instruction, so all students learn what's being taught (personal communication, 2016).

Successful differentiation can meet the diverse needs and abilities of students in the same classroom (Haelermans et al., 2015). Teachers who differentiate their instruction respond to learner needs in the way content is delivered (the content dimension of differentiation), the way content is learned (the process dimension), the ways students respond to the content (the product dimension), and how the learning environment is set up to facilitate learning (the learning environment dimension). Each of these characteristics of differentiation is designed to meet the needs of the individual learner and maximize the learning experiences of all students in an equitable manner.

While differentiation is posited as a useful tool to meet the needs of all learners, it also has been conflated with "academic tracking" debates in public schools (Ansalone, 2010). One major criticism of the approach is the viability of such a strategy as differentiation requires sophisticated and specialized instructional methods that often require adequate training and support to be effective. In particular, when considering more extensive class settings, the reality of using differentiation can be challenging and sometimes infeasible as many teachers lack more sophisticated and highly specialized instructional methods, and typically need adequate training, mentoring, and professional development to ensure they are using differentiated instructional techniques appropriately and effectively. Yet, other educators such as Tomlinson (2016) further argued that criticisms stem from a foundational understanding of the strategy as a whole as she noted differentiated instruction is not the "Individualized Instruction" of the 1970s. Accordingly, differentiation should be the practice of diversifying instructional strategies in a classroom to provide effective instructions to as many students as possible but not to create separate courses for every student (i.e., individualized instruction). Differentiated instruction is the intentional application of specific lesson planning and multiple learning approaches to support all learners (Tomlinson, 2001). 


\section{RESEARCH ON DIFFERENTIATION}

Differentiated instruction has been utilized in grades K-12 with positive academic gains for student learning. At the elementary level, significant academic growth was highlighted among diverse students in reading (Beecher \& Sweeny, 2008; Cusumano \& Muelier, 2007) and math (Beecher \& Sweeny, 2008; Grimes \& Stevens, 2009; Tomlinson, 2009). These gains were documented for students of various ability levels, across all racial/cultural groups, for English language learners, and students of numerous socioeconomic levels. At the middle and high school levels, the implementation of differentiated instruction typically occurs less frequently than in elementary schools. But, academic improvements are documented based on the use of differentiated instructional methods compared to students where teachers used traditional methods of instruction in science (Mastropieri et al., 2006) and biology and literature (Graham, 2009).

Use of differentiated instruction at the college level is even more limited and even fewer studies exist to further examine implementation possibly due to numerous reasons: (a) class sizes are typically quite large; (b) the number of contact hours with students is minimal; (c) designing several ways to assess students is time-consuming and challenging for professors who, in addition to teaching, have research and service obligations; and, finally, (d) ethical issues such as fairness in grading can be controversial (Ernst \& Ernst, 2005). Although limited, the following qualitative research outlines the impact of differentiation in higher education.

Livingston (2006) researched his undergraduate course with 33 preservice teachers using constructivist methods. The students were allowed to write reflections and responded to multiple prompts that were provided by the instructor. The majority of students stated that they appreciated opportunities to determine how they could complete assignments. The students further felt that choice in assignment delivery helped them to learn the information better and in a meaningful manner. Ernst and Ernst (2005) employed research on differentiation in an undergraduate political science course. The researchers used a Likert-style survey to examine student perceptions of differentiated instruction through open-ended questions. Out of 35 students in the class, the majority noted the course helped them reach their learning potential, collaborative group activities benefited their learning, and they appreciated having choices in exploring topics based on their interest. Tulbure (2011) utilized an experimental design to research her science methods courses using Kolb's learning styles categories to organize pre-service teachers in small groups of students who were taught with differentiated instruction versus those who were not. The control group was taught using differentiated instruction. While there were no significant differences found between the experimental and control groups on achievement tests, the experimental group that received differentiated instruction did improve more in achievement scores than the control group (Tulbure, 2011).

The existing research on differentiation is limited on use of differentiation at the college level. Common among the literature is the need for further research and practical strategies that highlight the benefits and applicability of differentiation in higher education. The next section provides applied examples of differentiation that can be used in college classrooms to promote equity.

\section{STRATEGIES TO PROMOTE AN EQUITY-BASED CLASSROOM}

An essential component of equity is educational access. As such, consideration should be given to the planning process to address how instruction will be differentiated for diverse learners in the classroom. In the college classroom, both in person and virtually, this means that teachers are more than just content area experts but, instead of creators of educational experiences. Teachers must differentiate instruction, as student learning styles, interests, strengths, and weaknesses exist even with adult learners. However, in addition to traditional means of differentiation, many scholars posit equitable approaches to differentiation encompass a critical need for identifying and including a student's cultural experiences and references in all aspects of teaching and learning (Ladson-Billings, 1995; Santamaria, 2009). So, a student's background and culture impact their learning experiences based on how the student receives information and processes it, and communicates. As such, to ensure equity through differentiation in classrooms, colleges, and 
universities must acknowledge the role culture plays in the classroom and engage students in culturally responsive ways (Hammonds, 2015).

\section{Examine Your Mindset to Establish an Equitable Learning Environment}

Differentiation for equity consists of more than just a pre-set list of teaching strategies. It entails a greater understanding of one's cultural lens and how that lens shapes the expectations of students in the learning environment. Ginott and Palmer (1972) argued that the teacher is the weather-maker in the classroom, with the teacher's demeanor and actions to students and situations being the determining factors as to whether students are inspired, humanized or dehumanized, appreciated or devalued. Research consistently proves that a teacher's emotional connection with a student contributes to academic growth and success (Hagenauer \& Volet, 2014; Hattie, 2009; Mojavezi \& Tamiz, 2012). That connection helps students to trust the instructor as a partner in the college classroom.

When considering the student as a partner in learning, the instructors need to examine her or his mindset about the students who make up the learning environment. While many college faculty are rooted in the belief that students can be successful if they work hard, limited awareness of implicit biases can and often does impact teaching practices and marginalized groups of students (Sue, 2010). In higher education, implicit bias refers to unconscious racial or socioeconomic bias towards students, which can be as persistent as explicit bias (Boysen, et. al 2009). Foremost, implicit biases can influence the expectations that we hold for diverse students, which can negatively impact their performance (Van den Bergh et al., 2010). Additionally, implicit biases can also lead us to misinformed perceptions about our students' abilities (Anderson-Clark et al., 2008). Essentially, awareness is critical to guide instructors with examining their mindset to examine personal beliefs and values and how these factors influence the expectations of students.

The Yale Poorvue Center for Teaching and Learning (2020) outlines effective strategies to disrupt implicit biases and facilitate a culturally responsive mindset and classroom environment. In particular, Reflective Teaching (RT) is highlighted as a useful tool for self-assessing teaching practices. It further requires instructors to examine pedagogy, support rationales and strengths for strategies, and identify areas of growth. Ultimately, RT requires instructors to deeply explore their underlying beliefs and teaching and learning and how those beliefs impact classroom practices.

To teach reflectively, instructors must think critically not only about their teaching, but also about problem-solving to ensure they are not relying on fixed personal norms. Additionally, we encourage instructors to use the guide (see table 1) as a reference while they engage in this reflection process. The take-home messages and prompts for reflection can help guide course redevelopment to implement differentiation that centers on equitable practices in the course. To this end, instructors can use various tools and approaches to learn from these sources and reflect upon their teaching to ensure equity in their classroom. 


\section{TABLE 1 \\ GUIDE FOR CONSIDERING FACULTY ROLES IN INCREASING EQUITY IN THE CLASSROOM}

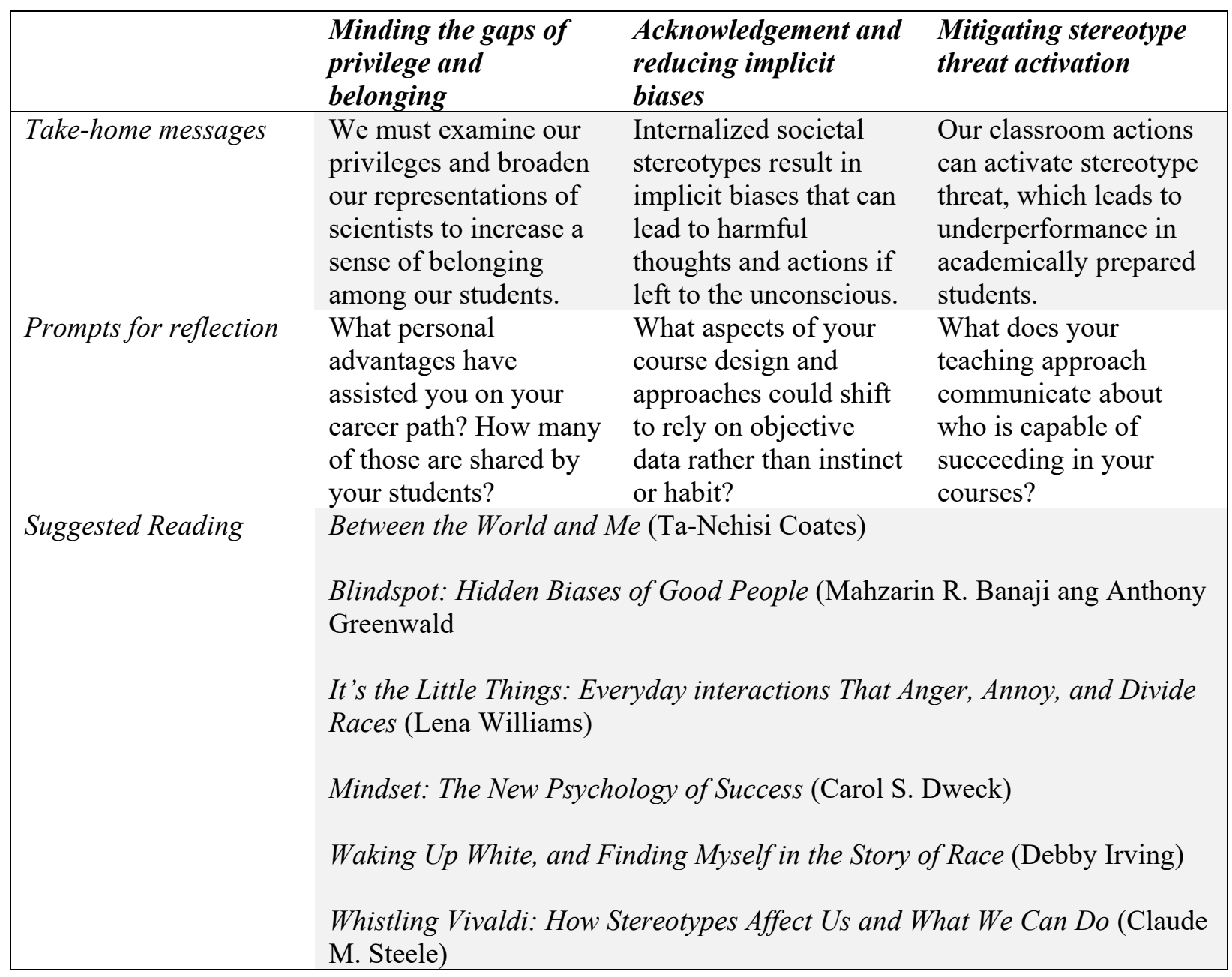

\section{Reflection Journals}

Reflection journals allow instructors to reflect on the details of their teaching immediately after class. They further provide for an ongoing narrative across their teaching over many semesters or years. But just by taking 5 to 10 minutes after class to do this, instructors can immediately process what went well and what could be improved, and effectively recall that information. Reflection questions might include, but are not limited to, the following: What went well today? What didn't go so well today? How did my students react to the content and delivery of the lesson? How can I improve this lesson?

\section{Teaching Inventories}

Many inventories have been developed to help instructors evaluate their pedagogical approaches (Pratt, Collins \& Selinger, 2001; Trigwell and Prosser, 2004; Wieman and Gilbert, 2014). Unlike observation tools, teaching inventories provide a low-stakes approach to self-assessing reflective teaching approaches. They further allow instructors to assess the extent to which teacher-centered and student-centered practices are employed in the classroom. The Equitable Classroom Practices Observation Checklist (2010) is a measure that combines resources that examine disproportionality and culturally responsive practices. This checklist includes a list of observable teacher behaviors in which the instructor can use to assess the implementation of equitable practices in her or his course. Examples include: (1) Acknowledges all 
students' comments, responses, questions, and contributions Uses affirming, correcting, or probing to acknowledge all students' responses, (2) Seeks multiple perspectives-validates all perspectives with responses such as: "That's one idea. Does anyone else have another?"; "That was one way to solve the problem. Who did it another way?"; "Who has an alternative view?"; (3) Uses multiple approaches to consistently monitor students' understanding of instruction, directions, procedures, processes, questions, and content. Moreover, the checklist provides actionable strategies that can easily be implemented in any course.

\section{Implement Culturally Responsive Content and Strategies to Improve Meaningful Engagement}

In addition to examining one's mindset to ensure an equitable learning environment through differentiation, instructors must learn how to implement content and strategies that are meaningful for students. As Gay (2000) points out, culture is deeply engrained in any teaching. Therefore, instructors must match the instructional strategies to the learning styles of diverse students. Meaningful learning occurs when learners can understand the purpose and relevance of their learning. As such, the content should be relevant to the students, and the instructional strategies should align with student learning in a way that allows students to construct meaning through their narratives (Hammond, 2014). This, according to Rhodes and Schmidt (2018), is essential in helping students connect course content to their background and the background and experiences of others.

\section{Use of Diverse Materials}

The use of multiethnic photos, pictures, and authors to illustrate concepts and content is essential for establishing a culturally responsive course and content materials (Ladson-Billings, 1995; Gay, 2000; Hammond, 2017). Diverse literature and aids provide students with opportunities to see themselves in the content. It is also important to include materials (readings, videos, audio recordings) that examine marginalized groups' experiences in ways that do not minimize these groups' experiences. Upon selecting diverse materials, instructors should consider materials that highlight multiple perspectives on each topic of the course instead of focusing on a single perspective. For example, when teaching about issues in society related to the focus of the course, include various experiences and views of people with different racial, religious, and socio-economic statuses. As a result, the use of diverse materials leads to greater engagement among students and increases equitable learning experiences and outcomes.

\section{Project-Based Learning}

Learning experiences should include opportunities for students to explore the world in which they live. Project-based learning (PBL) is a teaching method in which students gain knowledge and skills by working for an extended period of time to investigate and respond to an authentic, engaging, and complex question, problem, or challenge (Buck Institute for Learning, 2020). PBL provides students with options for relevant exploration of content in a meaningful way that allows them to "recognize students' cultural displays of learning" and the "use of cultural knowledge as a scaffold" (Hammond, 2014, p.15). Additionally, PBL places student inquiry at the core of the learning and provides the alternative to traditional teaching approaches that often parallel what Paulo Friere (1968) calls a banking approach to education. This banking approach is a method of teaching and learning where the students simply store the information relayed to them by the teacher and are mostly passive learners in their educational experiences.

On the contrary, PBL requires students to research and present their learning based on issues that are relevant to them and their communities. At the same time, the teacher serves as a facilitator during the process (Kean \& Kwe, 2014). Essentially, it allows instructors to bridge instruction with real-world experiences that are relevant to diverse student backgrounds.

\section{Create Spaces for Student Agency and Voice Through Collaborative Discussion}

Differentiation for equity further entails understanding student culture and ways of communication that engage students in meaningful ways that promote student agency and voice. The primary way students learn to develop a sense of agency and voice is through language and talk (Hammond, 2015). Discussion helps 
to process learning and expand on the thinking of others. Vygotsky (1978) coins this as the sociocultural theory of learning. When placed in the context of higher education, research asserts the majority of college classrooms are deficient in student agency and voice (Kasworm, 2005). To this end, instructors need to create spaces for such differentiation that allows for less teacher talk and more student talk grounded in collaborative discussion to improve learning outcomes.

\section{Structure Class Discussions for Equitable Participation}

Discussion in the college classroom has been linked to positive learning outcomes, critical thinking, and degree program completion (Noel, 2017). Often, patterns in group discussions emerge early in the semester in a way that can set the precedence for future discussions. So, it is essential for instructors to intentionally structure discussions in a way that promotes equity in the classroom. Shafer (2017) notes, "Students who are called on over and over may come to view their perspectives as the right perspectives. At the same time, students who do not perceive their teachers to be fair in soliciting participation may become less and less apt to contribute." Equitable class discussions not only encompass distinct ideas, but distinct voices. When teachers utilize equitable class discussions, they elevate historically marginalized voices, personalize learning, increase self efficacy, and reinforce critical skills such as tolerance and humility (Shaffer, 2017).

\section{Invite Student Self-Assessment of Participation}

Bledsoe and Baskin (2014) reports most students feel nervousness or anxiety about engaging in classroom discussion. He further goes on to note that at one time or another, many faculty have experienced a silent classroom. Howard (2015) suggests that periodic student self-assessment of their participation can increase learning and encourage more meaningful and frequent comments. One approach that is efficient is the use of a rubric for students to use to reflect on their participation. Rubric statements such as $1=\mathrm{I}$ do not participate in class discussions, I show minimum attentiveness to and engagement with the discussion, $2=\mathrm{I}$ try to participate in class discussions, but I tend to be passive, $3=$ I sometimes participate in class discussions and show minimum attentiveness to and engagement with the discussions, $4=I$ often participate in class discussions. I show comprehension of reading and the author's/director's positions. I make informed comments and arguments related to the material, and 5=I always participate in class discussions. When doing so I try to paraphrase, extend, amend, refute positions related to the material and respond to most of my group members. When students are given the opportunity to self assess throughout the course, it can enhance both the amount and quality of participation. Furthermore, it helps to build confidence and helps students hold themselves accountable for their contribution to the course, including participation.

\section{FINAL THOUGHTS AND CONCLUSION}

Differentiation for equity in higher education is essential for meeting the needs of an increasingly diverse student population. As a pedagogic tool, differentiation entails responding to learner needs in the way content is delivered (the content dimension of differentiation), the way content is learned (the process dimension), the ways students respond to the content (the product dimension), and the way in which the learning environment is set up to facilitate learning (the learning environment dimension) (Tomlinson, 2008). While research on differentiation in higher education is limited, studies show effective use of differentiation can help to improve students' motivation, academic achievement and constructively build on students' previous knowledge (Konstantinou-Katzi, 2013; Livingston, 2006; Munro, 2012). To this end, differentiation is necessary for student success in higher education.

Fostering high expectations for the achievement of all students requires teaching and learning to happen in a culturally supported, learner-centered context, whereby the strengths students bring to school are identified, nurtured, and utilized to promote student achievement (Richards, Brown, \& Forde, 2004). As such, differentiation for equity, requires a mind shift in the way educators think about teaching and learning in the classroom. This mind shift requires educators to acquiesce that schools should not affirm to students achieving prescribed norms, but should aim to enable them to maximize their potential (Dosch and Zidon, 
2014). Once this shift in mindset occurs, it is then that she or he can begin to appreciate the diversity present in the classroom. Ultimately, appreciation of the diversity in the classroom will help establish a framework that results in a classroom environment, curriculum, instructional materials and strategies that are relevant and meaningful to the student's abilities, needs, and experiences.

As we move forward in the commitment to provide students with equitable learning opportunities through differentiation, we must understand equitable does not always mean fair. Equity implies that students are provided access to opportunities and resources based on individual needs. Since each student has varied needs in the classroom, this means students may require different tools to be successful. As such, when considering differentiated instruction for equity, one must meet students where they are in relation to their learning, experiences, and background, while creating educational spaces in which they can thrive and be successful. It is a mindset of developing learning content accessible for all students - a mindset focused on equity, not equality. Tomlinson (2017) put it best when she noted differentiation is, "shaking up" what goes on in the classroom so that students have multiple options for taking in information, making sense of ideas, and expressing what they learn" (p.1). To this end, differentiation becomes not an option, but an obligation on the part of the educator to ensure equity in the classroom.

\section{REFERENCES}

Anderson-Clark, T.N., Green, R.J., \& Henley, T.B. (2008). The relationship between first names and teacher expectations for achievement motivation. Journal of Language and Social Psychology, 27(1), 94-99. https://doi.org/10.1177\%2F0261927X07309514

Ansalone, G. (2010). Tracking: Educational differentiation or defective strategy. Educational Research Quarterly, 34(2), 3-17. Retrieved from https://search.proquest.com/docview/1417050908?accountid=15017

Beamish, W., \& Saggers, B. (2013). Diversity and differentiation. In Teaching early years: Curriculum, pedagogy and assessment (pp. 244-258). Allen \& Unwin.

Beecher, M., \& Sweeny, S.M. (2008). Closing the achievement gap with curriculum enrichment and differentiation: One school's story. Journal of Advanced Academics, 19(3), 502-530. https://doi.org/10.4219\%2Fjaa-2008-815

Bledsoe, T.S., \& Baskin, J.J. (2014). Recognizing student fear: The elephant in the classroom. College Teaching, 62(1), 32-41. https://doi.org/10.1080/87567555.2018.1472064

Boysen, G.A., Vogel, D.L., Cope, M.A., \& Hubbard, A. (2009). Incidents of bias in college classrooms: Instructor and student perceptions. Journal of Diversity in Higher Education, 2(4), 219. https://doi.org/10.1037/a0017538

Buck Institute for Learning. (2020). What is PBL? Retrieved from https://www.pblworks.org/what-is-pbl

Cusumano, C., \& Mueller, J. (2007). How Differentiated Instruction Helps Struggling Students. Leadership, 36(4), 8-10. Retrieved from https://eric.ed.gov/?redir=http\%3a\%2f\%2fwww.acsa.org\%2fpublications\%2fpub_leadership.cfm

Dosch, M., \& Zidon, M. (2014). "The Course Fit Us": Differentiated Instruction in the College Classroom. International Journal of Teaching and Learning in Higher Education, 26(3), 343357. doi:http://dx.doi.org/10.1177/00224669060400030101

Ernst, H.R., \& Ernst, T.L. (2005). The promise and pitfalls of differentiated instruction for undergraduate political science courses: Student and instructor impressions of an unconventional teaching strategy. Journal of Political Science Education, 1(1), 39-59. https://doi.org/10.1080/15512160590907513

Freire, P. (1972). Pedagogy of the Oppressed. Trans. Myra Bergman Ramos. New York: Herder. Gay, G. (2002). Preparing for culturally responsive teaching. Journal of Teacher Education, 53(2), 106116. https://doi.org/10.1177\%2F0022487102053002003

Ginott, H.G., \& Palmer, M. (1972). Teacher and child: A book for parents and teachers. New York: Macmillan. 
Graham, K.J. (2009). Mandated implementation of differentiated instruction effectiveness examined. Unpublished doctoral dissertation. Walden University. (UMI No: 3366972).

Great Lakes Equity. (2010). Equitable Classroom Practices Observation Checklist. Retrieved from https://greatlakesequity.org/sites/default/files/201001011005_equity_tool.pdf

Haelermans, C., Ghysels, J., \& Prince, F. (2015). Increasing performance by differentiated teaching? Experimental evidence of the student benefits of digital differentiation. British Journal of Educational Technology, 46(6), 1161-1174. https://doi.org/10.1111/bjet.12209

Hagenauer, G., \& Volet, S.E. (2014). Teacher-student relationship at university: An important yet underresearched field. Oxford Review of Education, 40(3), 370-388.

https://doi.org/10.1111/bjet.12209. Retrieved from

http://www.tandfonline.com/10.1080/00228958.2012.654719

Hammond, Z. (2014). Culturally responsive teaching and the brain: Promoting authentic engagement and rigor among culturally and linguistically diverse students. Corwin Press.

Kappler Hewitt, K., \& Weckstein, D.K. (2012). Programs in Practice: Differentiated Instruction: Begin with Teachers! Kappa Delta Pi Record, 48(1), 35-46.

https://doi.org/10.1080/00228958.2012.654719

Kasworm, C. (2005). Adult student identity in an intergenerational community college classroom. Adult Education Quarterly, 56(1), 3-20. https://doi.org/10.1177/0741713605280148

Kean, A.C., \& Kwe, N.M. (2014). Meaningful learning in the teaching of culture: The project based learning approach. Journal of Education and Training Studies, 2(2), 189-197. https://doi.org/10.11114/jets.v2i2.270

Konstantinou-Katzi, P., Tsolaki, E., Meletiou-Mavrotheris, M., \& Koutselini, M. (2013). Differentiation of teaching and learning mathematics: An action research study in tertiary education.

International Journal of Mathematical Education in Science and Technology, 44(3), 332-349. https://doi.org/10.1080/0020739X.2012.714491

Livingston, D. (2006). Differentiated instruction and assessment in the college classroom. Reaching Through Teaching: A Journal of the Practice, Philosophy and Scholarship of College Teaching, 16(2), 17-31. Retrieved from http://www.isetl.org/ijtlhe/

Mastropieri, M.A., Scruggs, T.E., Norland, J.J., Berkeley, S., McDuffie, K., Tornquist, E.H., \& Connors, N. (2006). Differentiated curriculum enhancement in inclusive middle school science: Effects on classroom and high-stakes tests. The Journal of Special Education, 40(3), 130-137. https://doi.org/10.1177\%2F00224669060400030101

McGee Banks, C.A., \& Banks, J.A. (1995). Equity pedagogy: An essential component of multicultural education. Theory Into Practice, 34(3), 152-158. https://doi.org/10.1080/00405849509543674

Mojavezi, A., \& Tamiz, M.P. (2012). The Impact of Teacher Self-efficacy on the Students' Motivation and Achievement. Theory \& Practice in Language Studies, 2(3), 483-491.

https://doi.org/10.4304/tpls.2.3

Munro, J. (2012, August 27). Effective strategies for implementing differentiated instruction [Paper presentation]. 2012 - School Improvement: What does research tell us about effective strategies? Retrieved from https://research.acer.edu.au/research_conference/RC2012/27august/14

Nold, H. (2017). Using Critical Thinking Teaching Methods to Increase Student Success: An Action Research Project. International Journal of Teaching and Learning in Higher Education, 29(1), 17-32. http://www.isetl.org/ijtlhe/

Pliner, S.M., \& Johnson, J.R. (2004). Historical, theoretical, and foundational principles of universal instructional design in higher education. Équity \& Excellence in Education, 37(2), 105-113. https://doi.org/10.1080/10665680490453913

Pratt, D.D., Collins, J.B., \& Selinger, S.J. (2001, April). Development and use of the Teaching Perspectives Inventory (TPI). In Annual meeting of the American Educational Research Association. Seattle Washington.

Rhodes, C.M., \& Schmidt, S.W. (2018). Culturally Responsive Teaching in the Online Classroom. eLearn, 1(11). https://doi.org/10.1145/3295776.3274756 
Richards, H., Brown, A., \& Forde, T. (2004). Practitioner brief: Addressing diversity in schools: Culturally responsive pedagogy. Retrieved from www. nccrest.org/Briefs/Diversity_Brief.pdf

Santamaria, L.J. (2009). Culturally responsive differentiated instruction: Narrowing gaps between best pedagogical practices benefiting all learners. Teachers College Record, 111(1), 214-247. Retrieved from http://www.tcrecord.org/content.asp?contentid $=15210$

Shafer, L. (2017, November 27). How to have an equitable class discussion. Usable Knowledge. Retrieved from https://www.gse.harvard.edu/news/uk/17/11/how-have-equitable-class-discussion

Sparks, S.D. (2015, January 28). Differentiated Instruction: A Primer. Education Week. Retrieved from https://www.edweek.org/ew/articles/2015/01/28/differentiated-instruction-aprimer.html?r=61882963

Sue, D.W. (2010). Microaggressions in everyday life: Race, gender, and sexual orientation. Hobekon, NJ: John Wiley \& Sons.

The Yale Poorvue Center for Teaching and Learning. (2020). Awareness of Implicit Biases. Retrieved from https://poorvucenter.yale.edu/ImplicitBiasAwareness

Tomlinson, C.A. (2017). How to differentiate instruction in academically diverse classrooms. Alexandria VA: ASCD.

Tomlinson, C.A., \& Imbeau, M.B. (2010). Leading and managing a differentiated classroom. ASCD.

Trigwell, K., \& Prosser, M. (2004). Development and use of the approaches to teaching inventory. Educational Psychology Review, 16(4), 409-424. https://doi.org/10.1007/s10648-004-0007-9

Tulbure, C. (2011). Differentiated instruction for pre-service teachers: An experimental investigation. Procedia-Social and Behavioral Sciences, 30, 448-452. https://doi.org/10.1016/j.sbspro.2011.10.088

Van den Bergh, L., Denessen, E., Hornstra, L., Voeten, M., \& Holland, R.W. (2010). The implicit prejudiced attitudes of teachers: Relations to teacher expectations and the ethnic achievement gap. American Educational Research Journal, 47(2), 497-527. https://doi.org/10.3102\%2F0002831209353594

Vygotsky, L. (1978). Mind in society. Cambridge: Harvard.

Weingarten, H.P., \& Deller, F. (2011). The benefits of greater differentiation of Ontario's university sector. Higher Education Quality Council of Ontario.

Wieman, C., \& Gilbert, S. (2014). The teaching practices inventory: A new tool for characterizing college and university teaching in mathematics and science. CBE-Life Sciences Education, 13(3), 552569. https://doi.org/10.1187/cbe.14-02-0023 